Original Research Paper

\title{
The Inverse Kinematics of the Plane System 2-3 in a Mechatronic MP2R System, by a Trigonometric Method
}

\author{
${ }^{1}$ Relly Victoria Virgil Petrescu, ${ }^{2}$ Raffaella Aversa, ${ }^{2}$ Antonio Apicella, \\ ${ }^{3}$ Samuel Kozaitis, ${ }^{4}$ Taher Abu-Lebdeh and ${ }^{1}$ Florian Ion Tiberiu Petrescu \\ ${ }^{1}$ ARoTMM-IFToMM, Bucharest Polytechnic University, Bucharest, (CE) Romania \\ ${ }^{2}$ Advanced Material Lab, Department of Architecture and Industrial Design, \\ Second University of Naples, 81031 Aversa (CE) Italy \\ ${ }^{3}$ Florida Institute of Technology, USA \\ ${ }^{4}$ North Carolina A and T State University, USA
}

\section{Article history}

Received: 08-12-2017

Revised: $13-12-2017$

Accepted: 20-12-2017

Corresponding Author: Florian Ion Tiberiu Petrescu ARoTMM-IFToMM, Bucharest Polytechnic University, Bucharest, (CE), Romania E-mail: scipub02@gmail.com

\begin{abstract}
Robots have penetrated today in almost all industrial fields, being much more precise than humans in the execution of operations, but also faster, more dynamic, more stable and more resilient, working $24 \mathrm{~h}$ of the $24 \mathrm{~h}$ possible, in any season, breaks, holidays, vacations and especially without getting sick. The most important fact is that they can also perform special operations that man can't do. So, for example, they can work in toxic, contaminated, mined, dangerous, or airless environments (in the cosmos, under water or underground), they can also position the parts very precisely so they can be used for fine, special processing at high precision operations, excellent mechanical processing, exceptional medical operations and even in all medical operations today, helping the doctor manage the patient's surgery with amazing precision, especially when it comes to open heart, brain, kidneys, liver, etc. Robots should not be fed and yet they can have an extremely long life. They can help us conquer both the underwater spaces and the cosmic spaces. Robots have stunning work precision and a faster execution speed than a man. In addition, their very precise positioning makes robot operations a great advantage, which can no longer be neglected. In repetitive and tiring work they are irreplaceable. The most commonly used anthropomorphic robotic mechatronic systems, which are currently being used, have been studied by eliminating the heavy, matrix 3D spatial system, the study being simplified in a plan by considering the main work plan of the system and the plan, the rotation required to restore the spatial parameters of the anthropomorphic 3D system. In other words, we can greatly ease the work of the anthropomorphic robot engineer by moving from 3D systems to a $2 \mathrm{D}$ system. In this study we will study the inverse cinematics of the plan system, 2D, as the most important one. In general, end effector positions are known (required) and the positions of the 2D module elements and the necessary rotations of the actuators for their creation must be determined. In the kinematics we know the kinematic parameters $\mathrm{x}_{\mathrm{M}}$ and $\mathrm{y}_{\mathrm{M}}$, which represent the scaled coordinates of the point $\mathrm{M}$ (endeffector $\mathrm{M}$ ) and must be determined by analytical calculations the parameters $\varphi_{20}$ and $\varphi_{30}$.
\end{abstract}

Keywords: Anthropomorphic Robots, Inverse Kinematics, 3D Calculation, 2D Calculation, A Trigonometric Method 


\section{Introduction}

The most commonly used anthropomorphic robotic mechatronic systems, which are currently being used, have been studied by eliminating the heavy, matrix 3D spatial system, the study being simplified in a plan by considering the main work plan of the system and the plan, the rotation required to restore the spatial parameters of the anthropomorphic 3D system.

In other words, we can greatly ease the work of the anthropomorphic robot engineer by moving from 3D systems to a $2 \mathrm{D}$ system. In this study we will study the inverse cinematics of the plan system, $2 \mathrm{D}$, as the most important one. In general, end effector positions are known (required) and the positions of the 2D module elements and the necessary rotations of the actuators for their creation must be determined. In the kinematics we know the kinematic parameters $\mathrm{x}_{\mathrm{M}}$ and $\mathrm{y}_{\mathrm{M}}$, which represent the scaled coordinates of the point $\mathrm{M}$ (endefactor $\mathrm{M}$ ) and must be determined by analytical calculations the parameters $\varphi_{20}$ and $\varphi_{30}$. First we determine the intermediate parameters $\mathrm{d}$ and $\varphi$ with already known (3) relations.

Robots have penetrated today in almost all industrial fields, being much more precise than humans in the execution of operations, but also faster, more dynamic, more stable and more resilient, working $24 \mathrm{~h}$ of the $24 \mathrm{~h}$ possible, in any season, breaks, holidays, vacations and especially without getting sick.

The most important fact is that they can also perform special operations that man can't do. So, for example, they can work in toxic, contaminated, mined, dangerous, or airless environments (in the cosmos, under water or underground), they can also position the parts very precisely so they can be used for fine, special processing at high precision operations, excellent mechanical processing, exceptional medical operations and even in all medical operations today, helping the doctor manage the patient's surgery with amazing precision, especially when it comes to open heart, brain, kidneys, liver, etc.

Robots should not be fed and yet they can have an extremely long life. They can help us conquer both the underwater spaces and the cosmic spaces.

Robots have stunning work precision and a faster execution speed than a man. In addition, their very precise positioning makes robot operations a great advantage, which can no longer be neglected. In repetitive and tiring work they are irreplaceable.

Today the moving mechanical systems are utilized in almost all vital sectors of humanity (Reddy et al., 2012). The robots are able to process integrated circuits (Aldana et al., 2013) sizes micro and nano, on which the man they can be seen only with electron microscopy (Lee, 2013). Dyeing parts in toxic environments, working in chemical and radioactive environments (Padula and Perdereau, 2013; Perumaal and Jawahar, 2013), or at depths and pressures at the deep bottom of huge oceans, or conquest of cosmic space and visiting some new exoplanets, are with robots systems possible (Dong et al., 2013) and were turned into from the dream in reality (Garcia et al., 2007), because of use of mechanical platforms sequential gearbox (Cao et al., 2013; Petrescu, 2009).

The man will be able to carry out its mission supreme (Tang et al., 2013; Tong et al., 2013), conqueror of new galaxies (Flavio de Melo et al., 2012), because of mechanical systems sequential gear-box (robotics systems) (Garcia-Murillo et al., 2013).

Robots were developed and diversified (Lin et al., 2013), different aspects (He et al., 2013), but today, they start to be directed on two major categories: Systems serial (Liu et al., 2013; Petrescu and Petrescu, 2011b) and parallel systems (Petrescu and Petrescu, 2012c). Parallel systems are more solid (Tabaković et al., 2013; Wang et al., 2013) but more difficult to designed and handled and for this reason, the serial systems were those which have developed the most. In medical operations or radioactive environments are preferred mobile systems parallel, because of their high accuracy positioning.

As examples of such combined mechanisms, several kinematic schemes of gears and gears can be observed, presented by Kojevnikov (1969), (Autorenkollektiv, 1968), Saskin (1963; 1971), Maros (1958), Rehwald and Luck (200; 2001), Antonescu (1993; 2003; Antonescu and Mitrache, 1989).

The main problems with plane and spatial gears and gears refer to kinematic analysis and geometrickinematic synthesis under certain conditions imposed by technological processes, Bruja and Dima (2011), Buda and Mateucă (1989), Luck and Modler (1995), Niemeyer (2000), Tutunaru (1969), Popescu (1977), Braune (2000), Dudita (1989), Lichtenheldt (1995), Lederer (1993), Lin (1999), Modler and Wadewitz (1998; 2001; Modler, 1979), Neumann (1979; 2001), Stoica (1977), Petrescu and Petrescu (2011c; 2011d; Petrescu, 2012d; 2012e); (Petrescu, 2016; Petrescu et al., 2017a; 2017b; 2017c; 2017d; 2017e; 2017f; 2017g; 2017h; 2017i; 2017j; 2017k; 2017l; 2017m; 2017n; 2017o; 2017p; 2017q; Aversa et al., 2017a; 2017b; 2017c; 2017d; 2017e; 2016a; 2016b; 2016c; 2016d; 2016e; 2016f; 2016g; 2016h; 2016i; 2016j; 2016k; 2016l; 2016m; 2016n; 2016o; Mirsayar et al., 2017; Petrescu and Petrescu, 2016a; 2016b; 2016c, 2013a; 2013b; 2013c; 2013d, 2012a; 2012b; 2012c; 2012d; 2011a; 2011b; Petrescu, 2012a; 2012b; 2012c, 2009; Petrescu and Calautit, 2016a; 2016b; Petrescu et al., 2016a; 2016b; Maros, 1958; Modler and Wadewitz, 2001; Manolescu, 1968; Margine, 1999). 


\section{Materials and Methods; the Trigonometric Method}

Figure 1 shows the geometric-kinematic scheme of a base structure $3 R$.

From this platform you can study by adding any other modern n-R scheme.

The platform (system) of Fig. 1 has three degrees of mobility, made by three actuators (electric motors) or actuators. The first electric motor trains the entire system in a rotation motion around a vertical axis $\mathrm{O}_{0} \mathrm{z}_{0}$. The motor (actuator) number 1 is mounted on the fixed member (bay, 0) and drives the mobile element 1 in a rotation motion around a vertical axis. On the mobile element 1 , then all the other components (components) of the system are built.

There follows a planar (vertical) cinematic chain consisting of two movable elements and two kinematic motor couplings. It is the movable kinematic elements 2 and 3 , the assembly 2,3 being moved by the second actuator mounted in the coupling A fixed on the element 1. Thus the second electric motor fixed by the element 1 will drive the element 2 in a relative rotation relative to element 1 , but automatically it will move the entire kinematic chain 2-3.

The last actuator (electric motor) fixed by element 2 in B will rotate element 3 (relative to 2).

The rotation $\varphi_{10}$ made by the first actuator is also relative (between elements 1 and 0 ) and absolute (between elements 1 and 0 ).
The rotation $\varphi_{20}$ of the second actuator is also relative (between elements 2 and 1) and absolute (between elements 2 and 0 ) due to the positioning of the system.

The rotation $\theta=\varphi_{32}$ of the third actuator is only relative (between elements 3 and 2), the corresponding absolute (between elements 3 and 0 ) being a function of $\theta=\varphi_{32}$ and $\varphi_{20}$.

The kinematic chain 2-3 (made up of moving kinematic elements 2 and 3 ) is a planar cinematic chain that falls into one plane or one or more parallel planes. It is a special cinematic system that will be studied separately. The kinematic coupler A $\left(\mathrm{O}_{2}\right)$ and $\mathrm{B}\left(\mathrm{O}_{3}\right)$ become the first fixed coupler and the second movable coupler, both of which are $\mathrm{C} 5$ cinematic couplers, of rotation.

The kinematic chain 2-3 having the degree of mobility 2 must be driven by two motors.

It is preferred that the two actuators are two electric, DC, or alternating motors. The action can also be done with other engines. Hydraulic, pneumatic, sonic, etc.

The schematic diagram of the planar kinematic chain 2-3 (Fig. 2) resembles its kinematic scheme.

The guide element 2 is connected to the fixed element 1 by the motor coupler $\mathrm{O}_{2}$ and the drive element 3 is connected to the mobile element 2 by the motor coupler $\mathrm{O}_{3}$.

This results in a two-degree open cinematic chain made by the two actuators, ie the two electric motors mounted in the kinematic couplers $\mathrm{A}$ and $\mathrm{B}$ or $\mathrm{O}_{2}$ or $\mathrm{O}_{3}$.

Figure 3 shows the kinematic diagram of the open 23 chain (Petrescu, 2014).

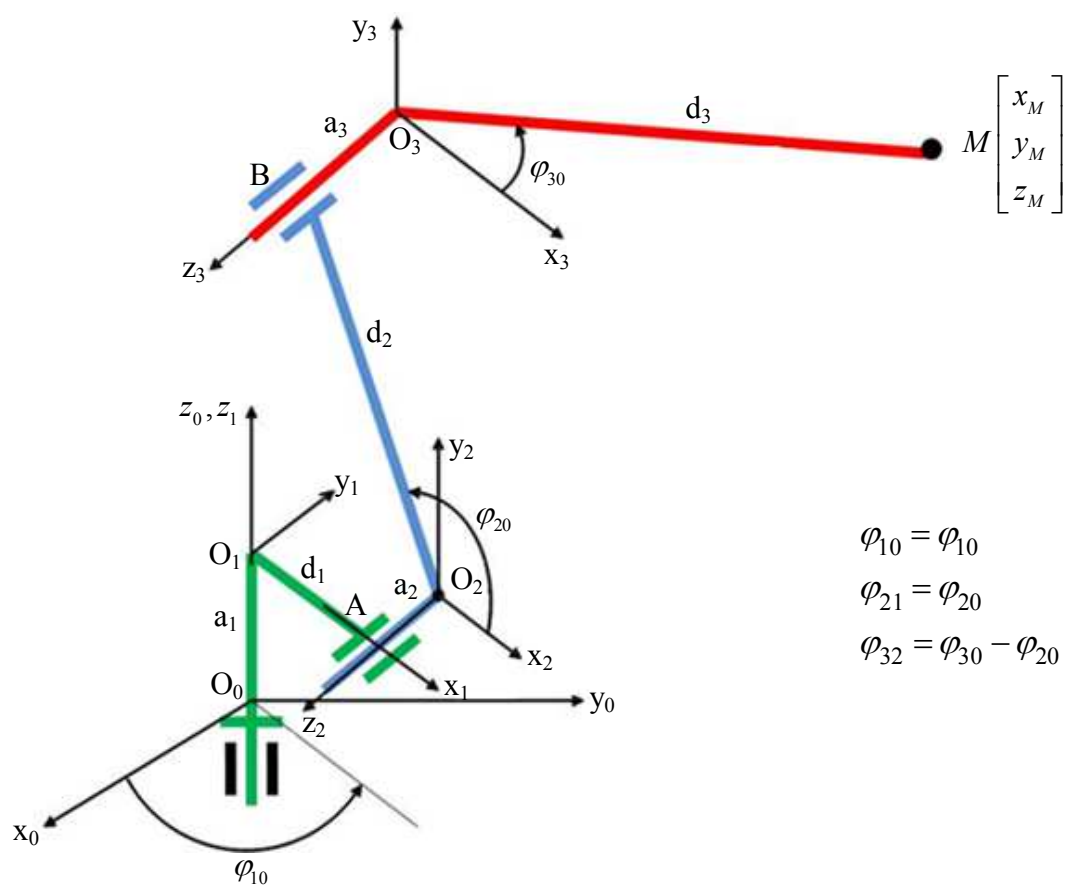

Fig. 1: The geometric-kinematic scheme of a base structure 3R 


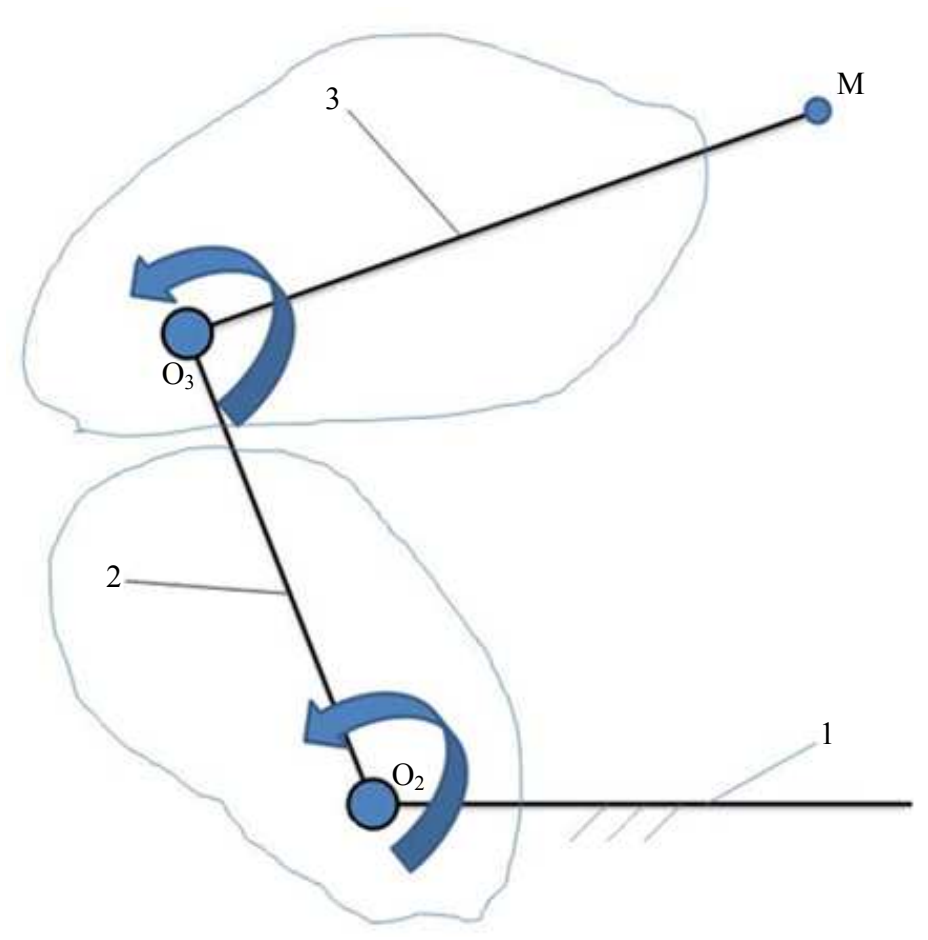

Fig. 2: The schematic diagram of the planar kinematic chain 2-3 bound to the element 1 considered to be fixed

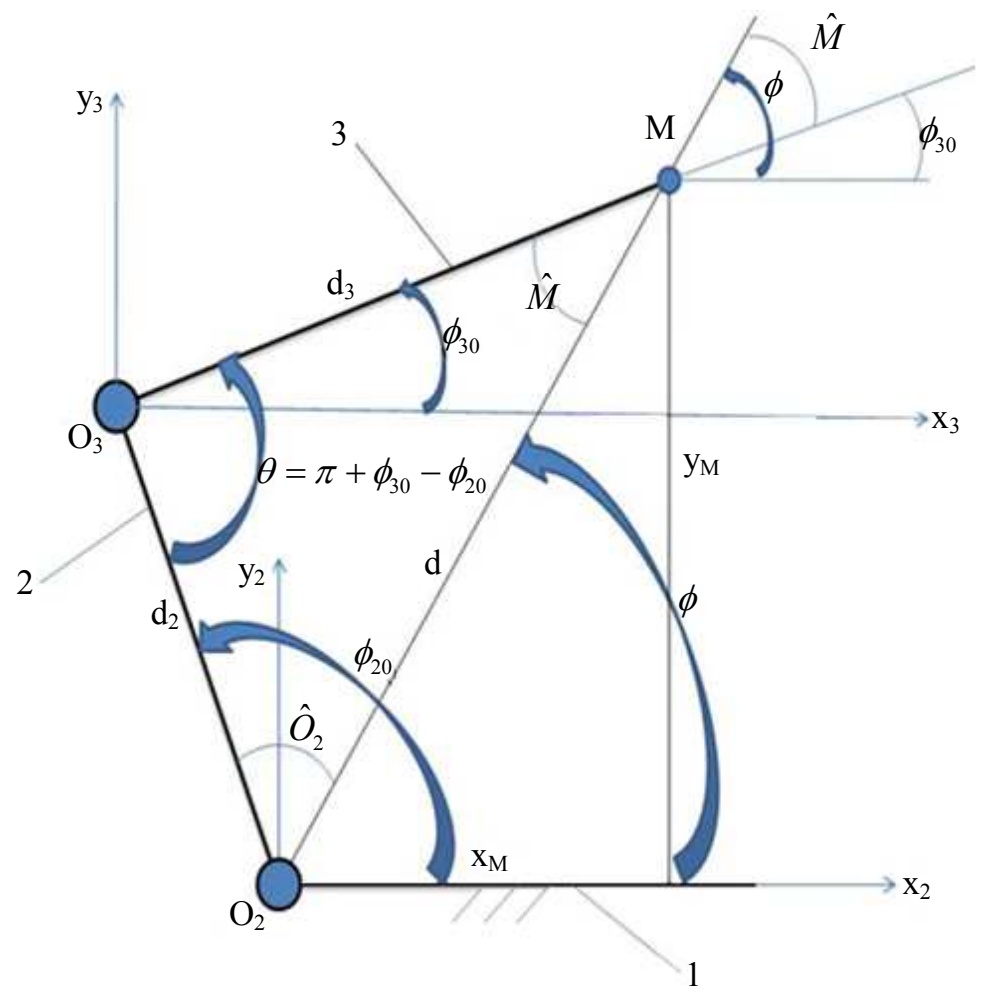

Fig. 3: The kinematic scheme of the planar kinematic chain 2-3 bound to element 1 considered fixed

In the kinematics we know the kinematic parameters $\mathrm{x}_{\mathrm{M}}$ and $\mathrm{y}_{\mathrm{M}}$, which represent the scaled coordinates of the point $\mathrm{M}$ (endefactor $\mathrm{M}$ ) and must be determined by analytical calculations the parameters $\varphi_{20}$ and $\varphi_{30}$. First we determine the intermediate parameters $d$ and $\varphi$ with already known (1) relations: 


$$
\left\{\begin{array}{l}
d^{2}=x_{M}^{2}+y_{M}^{2} ; d=\sqrt{x_{M}^{2}+y_{M}^{2}} \\
\cos \varphi=\frac{x_{M}}{d}=\frac{x_{M}}{\sqrt{x_{M}^{2}+y_{M}^{2}}} ; \\
\sin \varphi=\frac{y_{M}}{d}=\frac{y_{M}}{\sqrt{x_{M}^{2}+y_{M}^{2}}} \\
\varphi=\operatorname{semn}(\sin \varphi) \cdot \arccos (\cos \varphi)
\end{array}\right.
$$

In the triangle of some $\mathrm{O}_{2} \mathrm{O}_{3} \mathrm{M}$ we know the lengths of its three sides, $d^{2}, d^{3}$ (constants) and $d$ (variable), so that all the other elements of the triangle, namely its angles and the trigonometric functions of (we are particularly interested in sin and cos).

Different methods can be used to determine the angles $\varphi_{20}$ and $\varphi_{30}$, of which two of them (as being most representative) will be presented: The trigonometric method and the geometric method.

\section{Determination of Positions}

Scalar position equations are written (2):

$$
\left\{\begin{array}{l}
d_{2} \cdot \cos \varphi_{20}+d_{3} \cdot \cos \varphi_{30}=x_{M} \\
d_{2} \cdot \sin \varphi_{20}+d_{3} \cdot \sin \varphi_{30}=y_{M} \\
\cos ^{2} \varphi_{20}+\sin ^{2} \varphi_{20}=1 \\
\cos ^{2} \varphi_{30}+\sin ^{2} \varphi_{30}=1
\end{array}\right.
$$

The problem of this two scalar, trigonometric, two unknown equations $\left(\varphi_{20}\right.$ and $\left.\varphi_{30}\right)$ is that they have been transcribed (they are trigonometric, transcendental equations, where the unknown does not appear directly $\varphi_{20}$ but in the form of $\cos \varphi_{20}$ and $\sin \varphi_{20}$, so in reality in the two trigonometric equations we no longer have two unknown but four: $\cos \varphi_{20}, \sin \varphi_{20}, \cos \varphi_{30}$ and $\sin \varphi_{30}$ ).

To solve the system we need two more equations, so in the system (2) we have added two more trigonometric equations, namely the golden basic trigonometric equations as it is called for the angle $\varphi_{20}$ and separated for the angle $\varphi_{30}$.

In order to solve the first two equations of the system (2) we write in the form (3):

$$
\left\{\begin{array}{l}
d_{2} \cdot \cos \varphi_{20}-x_{M}=-d_{3} \cdot \cos \varphi_{30} \\
d_{2} \cdot \sin \varphi_{20}-y_{M}=-d_{3} \cdot \sin \varphi_{30}
\end{array}\right.
$$

Each equation of the system (3) rises to square, then sums up both equations (raised to square) and obtains the equation of form (4):

$$
\begin{aligned}
& d_{2}^{2} \cdot\left(\cos ^{2} \varphi_{20}+\sin ^{2} \varphi_{20}\right)+x_{M}^{2}+y_{M}^{2} \\
& -2 \cdot d_{2} \cdot x_{M} \cdot \cos \varphi_{20}-2 \cdot d_{2} \cdot y_{M} \cdot \sin \varphi_{20} \\
& =d_{3}^{2} \cdot\left(\cos ^{2} \varphi_{30}+\sin ^{2} \varphi_{30}\right)
\end{aligned}
$$

Now is the time to use the two trigonometric gold "equations of gold" written at the end of the system (2), with which Equation 4 gets simplified form (5):

$$
\begin{aligned}
& d_{2}^{2}+x_{M}^{2}+y_{M}^{2}-2 \cdot d_{2} \cdot x_{M} \cdot \cos \varphi_{20} \\
& -2 \cdot d_{2} \cdot y_{M} \cdot \sin \varphi_{20}=d_{3}^{2}
\end{aligned}
$$

The terms of Equation 5 are arranged in the more convenient form (6):

$$
\begin{aligned}
& d_{2}^{2}-d_{3}^{2}+x_{M}^{2}+y_{M}^{2} \\
& =2 \cdot d_{2} \cdot\left(x_{M} \cdot \cos \varphi_{20}+y_{M} \cdot \sin \varphi_{20}\right)
\end{aligned}
$$

Divide Equation 6 with $2 . d_{2}$ and result in a new form (7):

$x_{M} \cdot \cos \varphi_{20}+y_{M} \cdot \sin \varphi_{20}=\frac{d_{2}^{2}-d_{3}^{2}+x_{M}^{2}+y_{M}^{2}}{2 \cdot d_{2}}$

From Fig. 3 or System (1) the relationship (8) is noted:

$x_{M}^{2}+y_{M}^{2}=d^{2}$

Insert (8) into (7) and amplify the right fraction with $d$ so that the expression (7) takes the convenient form (9):

$x_{M} \cdot \cos \varphi_{20}+y_{M} \cdot \sin \varphi_{20}=\frac{d_{2}^{2}+d^{2}-d_{3}^{2}}{2 \cdot d_{2} \cdot d} \cdot d$

Now is the moment of entering the cosine expression of the $\mathrm{O}_{2}$ angle, depending on the sides of the triangle of some $\mathrm{O}_{2} \mathrm{O}_{3} \mathrm{M}(10)$ :

$\cos \hat{O}_{2}=\frac{d_{2}^{2}+d^{2}-d_{3}^{2}}{2 \cdot d_{2} \cdot d}$

With relation (10) Equation 9 takes the simplified form (11):

$x_{M} \cdot \cos \varphi_{20}-d \cdot \cos \hat{O}_{2}=-y_{M} \cdot \sin \varphi_{20}$

We want to eliminate $\sin \varphi_{20}$, which is why we have isolated the term in $\sin$ and square Equation 11, because by using the trigonometric gold equation of the angle $\varphi_{20}$, we transform sin into cos, the equation becoming one of the second degree in $\cos \varphi_{20}$. After picking up the square (11) it takes shape (12):

$$
\begin{aligned}
& x_{M}^{2} \cdot \cos ^{2} \varphi_{20}+d^{2} \cdot \cos ^{2} \hat{O}_{2} \\
& -2 \cdot d \cdot x_{M} \cdot \cos \hat{O}_{2} \cdot \cos \varphi_{20} \\
& =y_{M}^{2} \cdot \sin ^{2} \varphi_{20}
\end{aligned}
$$


The gold formula is used so that the expression (12) takes the form (13) which is conveniently arranged by grouping the terms into the shape (14):

$$
\begin{aligned}
& x_{M}^{2} \cdot \cos ^{2} \varphi_{20}+d^{2} \cdot \cos ^{2} \hat{O}_{2} \\
& -2 \cdot d \cdot x_{M} \cdot \cos \hat{O}_{2} \cdot \cos \varphi_{20} \\
& =y_{M}^{2}-y_{M}^{2} \cdot \cos ^{2} \varphi_{20} \\
& \left(x_{M}^{2}+y_{M}^{2}\right) \cdot \cos ^{2} \varphi_{20}-2 \cdot d \cdot x_{M} \cdot \cos \hat{O}_{2} \cdot \cos \varphi_{20} \\
& -\left(y_{M}^{2}-d^{2} \cdot \cos ^{2} \hat{O}_{2}\right)=0
\end{aligned}
$$

The determinant of the second-degree Equation 14 just obtained, is calculated with the relation (15):

$$
\begin{aligned}
& \Delta=d^{2} \cdot x_{M}^{2} \cdot \cos ^{2} \hat{O}_{2}+d^{2} \cdot\left(y_{M}^{2}-d^{2} \cdot \cos ^{2} \hat{O}_{2}\right) \\
& =d^{2} \cdot\left(x_{M}^{2} \cdot \cos ^{2} \hat{O}_{2}+y_{M}^{2}-d^{2} \cdot \cos ^{2} \hat{O}_{2}\right) \\
& =d^{2} \cdot\left(y_{M}^{2}-y_{M}^{2} \cdot \cos ^{2} \hat{O}_{2}\right) \\
& =d^{2} \cdot y_{M}^{2} \cdot\left(1-\cos ^{2} \hat{O}_{2}\right)=d^{2} \cdot y_{M}^{2} \cdot \sin ^{2} \hat{O}_{2}
\end{aligned}
$$

The second order radical of the determinant is expressed as (16):

$$
R=\sqrt{\Delta}=\sqrt{d^{2} \cdot y_{M}^{2} \cdot \sin ^{2} \hat{O}_{2}}=d \cdot y_{M} \cdot \sin \hat{O}_{2}
$$

The solutions of the second-degree equation in cosine (14) are written as (17):

$$
\begin{aligned}
& \cos \varphi_{20_{1,2}}=\frac{d \cdot x_{M} \cdot \cos \hat{O}_{2} \mp d \cdot y_{M} \cdot \sin \hat{O}_{2}}{d^{2}} \\
& =\frac{x_{M} \cdot \cos \hat{O}_{2} \mp y_{M} \cdot \sin \hat{O}_{2}}{d} \\
& =\frac{x_{M}}{d} \cdot \cos \hat{O}_{2} \mp \frac{y_{M}}{d} \cdot \sin \hat{O}_{2}
\end{aligned}
$$

Next, in solutions (17) we replace the corresponding trigonometric angle of functions $\varphi$, the expressions (17) obtaining the form (18):

$$
\begin{aligned}
& \cos \varphi_{20_{1,2}}=\frac{x_{M}}{d} \cdot \cos \hat{O}_{2} \mp \frac{y_{M}}{d} \cdot \sin \hat{O}_{2} \\
& =\cos \varphi \cdot \cos \hat{O}_{2} \mp \sin \varphi \cdot \sin \hat{O}_{2}=\cos \left(\varphi \pm \hat{O}_{2}\right) \\
& \cos \varphi_{20}=\cos \left(\varphi \pm \hat{O}_{2}\right)
\end{aligned}
$$

We now return to the Equation 11 that we order in form (19), in order to solve it in the sin. Equation 19 rises to square and using the trigonometric gold equation of the angle $\varphi_{20}$, form (20) is obtained:

$$
x_{M} \cdot \cos \varphi_{20}=d \cdot \cos \hat{O}_{2}-y_{M} \cdot \sin \varphi_{20}
$$

$$
\left\{\begin{array}{l}
x_{M}^{2} \cdot \cos ^{2} \varphi_{20}=d^{2} \cdot \cos ^{2} \hat{O}_{2}+y_{M}^{2} \cdot \sin ^{2} \varphi_{20} \\
-2 \cdot y_{M} \cdot d \cdot \cos \hat{O}_{2} \cdot \sin \varphi_{20} \\
x_{M}^{2}-x_{M}^{2} \cdot \sin ^{2} \varphi_{20}=d^{2} \cdot \cos ^{2} \hat{O}_{2}+y_{M}^{2} \cdot \sin ^{2} \varphi_{20} \\
-2 \cdot y_{M} \cdot d \cdot \cos \hat{O}_{2} \cdot \sin \varphi_{20} \\
\left(x_{M}^{2}+y_{M}^{2}\right) \cdot \sin ^{2} \varphi_{20}-2 \cdot y_{M} \cdot d \cdot \cos \hat{O}_{2} \cdot \sin \varphi_{20} \\
-\left(x_{M}^{2}-d^{2} \cdot \cos ^{2} \hat{O}_{2}\right)=0 \\
d^{2} \cdot \sin ^{2} \varphi_{20}-2 \cdot y_{M} \cdot d \cdot \cos \hat{O}_{2} \cdot \sin \varphi_{20} \\
-\left(x_{M}^{2}-d^{2} \cdot \cos ^{2} \hat{O}_{2}\right)=0
\end{array}\right.
$$

The discriminative of the second-degree Equation 20 in cosine takes the form (21):

$$
\begin{aligned}
& \Delta=y_{M}^{2} \cdot d^{2} \cdot \cos ^{2} \hat{O}_{2}+d^{2} \cdot\left(x_{M}^{2}-d^{2} \cdot \cos ^{2} \hat{O}_{2}\right) \\
& =d^{2} \cdot\left(x_{M}^{2}+y_{M}^{2} \cdot \cos ^{2} \hat{O}_{2}-x_{M}^{2} \cdot \cos ^{2} \hat{O}_{2}-y_{M}^{2} \cdot \cos ^{2} \hat{O}_{2}\right) \\
& =d^{2} \cdot\left(x_{M}^{2}-x_{M}^{2} \cdot \cos ^{2} \hat{O}_{2}\right)=d^{2} \cdot x_{M}^{2} \cdot \sin ^{2} \hat{O}_{2}
\end{aligned}
$$

The solutions of Equation 20 are written as (22):

$$
\begin{aligned}
& \sin \varphi_{20}=\frac{y_{M} \cdot d \cdot \cos \hat{O}_{2} \pm x_{M} \cdot d \cdot \sin \hat{O}_{2}}{d^{2}} \\
& =\frac{y_{M} \cdot \cos \hat{O}_{2} \pm x_{M} \cdot \sin \hat{O}_{2}}{d}=\frac{y_{M}}{d} \cdot \cos \hat{O}_{2} \pm \frac{x_{M}}{d} \cdot \sin \hat{O}_{2} \\
& =\sin \varphi \cdot \cos \hat{O}_{2} \pm \cos \varphi \cdot \sin \hat{O}_{2}=\sin \left(\varphi \pm \hat{O}_{2}\right) \\
& \sin \varphi_{20}=\sin \left(\varphi \pm \hat{O}_{2}\right)
\end{aligned}
$$

We obtained relations (23), from which the basic relationship is deduced (24):

$$
\begin{aligned}
& \left\{\begin{array}{l}
\cos \varphi_{20}=\cos \left(\varphi \pm \hat{O}_{2}\right) \\
\sin \varphi_{20}=\sin \left(\varphi \pm \hat{O}_{2}\right)
\end{array}\right. \\
& \varphi_{20}=\varphi \pm \hat{O}_{2}
\end{aligned}
$$

Repeat the procedure for determining the angle $\varphi_{30}$, starting again from the system (2), in which the first two transcendental equations are rewritten in the form (25) in order to eliminate the angle $\varphi_{20}$ this time:

$$
\left\{\begin{array}{l}
d_{2} \cdot \cos \varphi_{20}+d_{3} \cdot \cos \varphi_{30}=x_{M} \\
d_{2} \cdot \sin \varphi_{20}+d_{3} \cdot \sin \varphi_{30}=y_{M} \\
\cos ^{2} \varphi_{20}+\sin ^{2} \varphi_{20}=1 \\
\cos ^{2} \varphi_{30}+\sin ^{2} \varphi_{30}=1
\end{array}\right.
$$




$$
\left\{\begin{array}{l}
d_{2} \cdot \cos \varphi_{20}=x_{M}-d_{3} \cdot \cos \varphi_{30} \\
d_{2} \cdot \sin \varphi_{20}=y_{M}-d_{3} \cdot \sin \varphi_{30}
\end{array}\right.
$$

Raises the two equations of the system (25) to the square and assembles, resulting in the equation of form (26), which is arranged in more convenient forms (27) and (28):

$$
\begin{aligned}
& d_{2}^{2}=x_{M}^{2}+y_{M}^{2}+d_{3}^{2}-2 \cdot d_{3} \cdot x_{M} \cdot \cos \varphi_{30} \\
& -2 \cdot d_{3} \cdot y_{M} \cdot \sin \varphi_{30} \\
& x_{M} \cdot \cos \varphi_{30}+y_{M} \cdot \sin \varphi_{30}=d \cdot \frac{d^{2}+d_{3}^{2}-d_{2}^{2}}{2 \cdot d \cdot d_{3}} \\
& x_{M} \cdot \cos \varphi_{30}+y_{M} \cdot \sin \varphi_{30}=d \cdot \cos \hat{M}
\end{aligned}
$$

We want to determine it first on the basket so that we will initially isolate the term in the sin, Equation 28 being in the form (29), which by square-up generates expression (30), the expression which is arranged in the form (31):

$$
\begin{aligned}
& x_{M} \cdot \cos \varphi_{30}-d \cdot \cos \hat{M}=-y_{M} \cdot \sin \varphi_{30} \\
& x_{M}^{2} \cdot \cos ^{2} \varphi_{30}+d^{2} \cdot \cos ^{2} \hat{M} \\
& -2 \cdot d \cdot x_{M} \cdot \cos \hat{M} \cdot \cos \varphi_{30} \\
& =y_{M}^{2}-y_{M}^{2} \cdot \cos ^{2} \varphi_{30} \\
& d^{2} \cdot \cos ^{2} \varphi_{30}-2 \cdot d \cdot x_{M} \cdot \cos \hat{M} \cdot \cos \varphi_{30} \\
& -\left(y_{M}^{2}-d^{2} \cdot \cos ^{2} \hat{M}\right)=0
\end{aligned}
$$

Equation 31 is a second-degree equation in the cosine with the solutions given by the expression (32):

$$
\begin{aligned}
& \cos \varphi_{30} \\
& =\frac{d \cdot x_{M} \cdot \cos \hat{M} \pm \sqrt{d^{2} \cdot x_{M}^{2} \cdot \cos ^{2} \hat{M}+d^{2} \cdot\left(y_{M}^{2}-d^{2} \cdot \cos ^{2} \hat{M}\right)}}{d^{2}} \\
& =\frac{d \cdot x_{M} \cdot \cos \hat{M} \pm \sqrt{d^{2} \cdot y_{M}^{2} \cdot\left(1-\cos ^{2} \hat{M}\right)}}{d^{2}} \\
& =\frac{d \cdot x_{M} \cdot \cos \hat{M} \pm d \cdot y_{M} \cdot \sin \hat{M}}{d^{2}} \\
& =\frac{x_{M} \cdot \cos \hat{M} \pm \frac{y_{M}}{d} \cdot \sin \hat{M}=\cos \varphi \cdot \cos \hat{M} \pm \sin \varphi \cdot \sin \hat{M}}{d}=\cos (\varphi \mp \hat{M}) \\
& \cos \varphi_{30}=\cos (\varphi \mp \hat{M})
\end{aligned}
$$

We continue to write Equation 28 in the form (33), where the term is now isolated in the cosine for its elimination, in order to determine the sin:
$x_{M} \cdot \cos \varphi_{30}=d \cdot \cos \hat{M}-y_{M} \cdot \sin \varphi_{30}$

Equation 33 rises to square and obtains the equation of form (34), which is arranged in a convenient form (35):

$x_{M}^{2} \cdot\left(1-\sin ^{2} \varphi_{30}\right)=d^{2} \cdot \cos ^{2} \hat{M}+$

$+y_{M}^{2} \cdot \sin ^{2} \varphi_{30}-2 \cdot y_{M} \cdot d \cdot \cos \hat{M} \cdot \sin \varphi_{30}$

$d^{2} \cdot \sin ^{2} \varphi_{30}-2 \cdot y_{M} \cdot d \cdot \cos \hat{M} \cdot \sin \varphi_{30}$

$-\left(x_{M}^{2}-d^{2} \cdot \cos ^{2} \hat{M}\right)=0$

Expression (35) is an equation of the grade II in the sine which admits the solutions given by the relation (36):

$\sin \varphi_{30}$

$$
\begin{aligned}
& =\frac{d \cdot y_{M} \cdot \cos \hat{M} \mp \sqrt{d^{2} \cdot y_{M}^{2} \cdot \cos ^{2} \hat{M}+d^{2} \cdot\left(x_{M}^{2}-d^{2} \cdot \cos ^{2} \hat{M}\right)}}{d^{2}} \\
& =\frac{d \cdot y_{M} \cdot \cos \hat{M} \mp \sqrt{d^{2} \cdot x_{M}^{2} \cdot\left(1-\cos ^{2} \hat{M}\right)}}{d^{2}} \\
& =\frac{d \cdot y_{M} \cdot \cos \hat{M} \mp d \cdot x_{M} \cdot \sin \hat{M}}{d^{2}}
\end{aligned}
$$

$=\frac{y_{M}}{d} \cdot \cos \hat{M} \mp \frac{x_{M}}{d} \cdot \sin \hat{M}=\sin \varphi \cdot \cos \hat{M} \mp \cos \varphi \cdot \sin \hat{M}$

$=\sin (\varphi \mp \hat{M})$

$\sin \varphi_{30}=\sin (\varphi \mp \hat{M})$

The relations (37) from which the expression (38) is deduced are also retained:

$$
\begin{aligned}
& \left\{\begin{array}{l}
\cos \varphi_{30}=\cos (\varphi \mp \hat{M}) \\
\sin \varphi_{30}=\sin (\varphi \mp \hat{M})
\end{array}\right. \\
& \varphi_{30}=\varphi \mp \hat{M}
\end{aligned}
$$

\section{Results: Determination of Speeds and Accelerations}

\section{Velocities}

From the system (2), only the relations (39) required in the study of velocities at the reverse kinematics are retained. It starts from the relationship that links the cosine of the angle to the sides of the triangle, a relationship that is time dependent and thus the simpler written value (relations 40) is obtained:

$\left\{\begin{array}{l}\dot{\varphi}=\frac{\dot{y}_{M} \cdot \cos \varphi-\dot{x}_{M} \cdot \sin \varphi}{d} \\ \dot{d}=\frac{x_{M} \cdot \dot{x}_{M}+y_{M} \cdot \dot{y}_{M}}{d}\end{array}\right.$ 


$$
\left\{\begin{array}{l}
2 \cdot d_{2} \cdot d \cdot \cos O_{2}=d_{2}^{2}-d_{3}^{2}+d^{2} \\
2 \cdot d_{2} \cdot \dot{d} \cdot \cos O_{2}-2 \cdot d_{2} \cdot d \cdot \sin O_{2} \cdot \dot{O}_{2}=2 \cdot d \cdot \dot{d} \\
\Rightarrow \dot{O}_{2}=\frac{d_{2} \cdot \dot{d} \cdot \cos O_{2}-d \cdot \dot{d}}{d_{2} \cdot d \cdot \sin O_{2}}
\end{array}\right.
$$

The relationship (24) is derived and the angular velocity $\omega_{20} \equiv \dot{\varphi}_{20}$ (relationship 41 ) is obtained:

$$
\begin{aligned}
& \varphi_{20}=\varphi \pm \hat{O}_{2} \\
& \omega_{20} \equiv \dot{\varphi}_{20}=\dot{\varphi} \pm \dot{O}_{2}
\end{aligned}
$$

To determine $\omega_{20}$ (relation 41 ) we need $\dot{\varphi}$ to be computed from (39) and $\dot{O}_{2}$ determined by (40). In turn $\dot{O}_{2}$ it requires $\dot{d}$ for its calculation, which is also calculated from the system (39):

Input speeds $\dot{x}_{M}$ and $\dot{y}_{M}$ are known, are imposed as inputs, or are conveniently chosen, or can be calculated on the basis of imposed criteria.

Similarly, the angular velocity $\omega_{30} \equiv \dot{\varphi}_{30}$ is determined (42):

$$
\left\{\begin{array}{l}
2 \cdot d_{3} \cdot d \cdot \cos M=d_{3}^{2}-d_{2}^{2}+d^{2} \\
2 \cdot d_{3} \cdot \dot{d} \cdot \cos M-2 \cdot d_{3} \cdot d \cdot \sin M \cdot \dot{M}=2 \cdot d \cdot \dot{d} \\
\Rightarrow \dot{M}=\frac{d_{3} \cdot \dot{d} \cdot \cos M-d \cdot \dot{d}}{d_{3} \cdot d \cdot \sin M}
\end{array}\right.
$$

The relationship (38) is derived to obtain the angular velocity $\omega_{30} \equiv \dot{\varphi}_{30}$, (expression 43$)$. $\dot{\varphi}$ is calculated with the already known expression in the system (39) and $\dot{M}$ it is determined from the system (42) and with the help of the system (39) which determines also and $\dot{d}$ :

$$
\begin{aligned}
& \varphi_{30}=\varphi \mp \hat{M} \\
& \omega_{30} \equiv \dot{\varphi}_{30}=\dot{\varphi} \mp \dot{M}
\end{aligned}
$$

\section{Accelerations}

Derive (39) and we obtain the necessary relations (44) in the study of the accelerations in the inverse kinematics. The relation in the system (40) is derived a second time with the time and the system (45) is obtained:

$$
\left\{\begin{array}{l}
\ddot{\varphi}=\frac{\ddot{y}_{M} \cdot \cos \varphi-\ddot{x}_{M} \cdot \sin \varphi-\dot{y}_{M} \cdot \sin \varphi \cdot \dot{\varphi}-\dot{x}_{M} \cdot \cos \varphi \cdot \dot{\varphi}-\dot{d} \cdot \dot{\varphi}}{d} \\
\ddot{d}=\frac{\dot{x}_{M}^{2}+x_{M} \cdot \ddot{x}_{M}+\dot{y}_{M}^{2}+y_{M} \cdot \ddot{y}_{M}-\dot{d}^{2}}{d}
\end{array}\right.
$$

$$
\left\{\begin{array}{l}
2 \cdot d_{2} \cdot d \cdot \cos O_{2}=d_{2}^{2}-d_{3}^{2}+d^{2} \\
2 \cdot d_{2} \cdot \dot{d} \cdot \cos O_{2}-2 \cdot d_{2} \cdot d \cdot \sin O_{2} \cdot \dot{O}_{2}=2 \cdot d \cdot \dot{d} \\
\Rightarrow d_{2} \cdot d \cdot \sin O_{2} \cdot \dot{O}_{2}=d_{2} \cdot \dot{d} \cdot \cos O_{2}-d \cdot \dot{d} \\
\ddot{O_{2}}= \\
\frac{\ddot{d} d_{2} \cos O_{2}-\ddot{d} d-2 \dot{d} d_{2} \sin O_{2} \cdot \dot{O}_{2}-d d_{2} \cos O_{2} \cdot \dot{O}_{2}^{2}-\dot{d}^{2}}{d_{2} \cdot d \cdot \sin O_{2}}
\end{array}\right.
$$

Then the expression (41) is derived and the relation (46) generating the absolute angular acceleration $\varepsilon_{2} \equiv \varepsilon_{20}$, which is calculated with $\ddot{\varphi}$ the output from the system (44) and with $\ddot{O}_{2}$ extracted from the system (45) and for $\ddot{O}_{2}$ to be obtained it is also necessary $\ddot{d}$ dermined also from (44):

$\omega_{20} \equiv \dot{\varphi}_{20}=\dot{\varphi} \pm \dot{O}_{2}$

$\varepsilon_{2} \equiv \varepsilon_{20}=\dot{\omega}_{20} \equiv \ddot{\varphi}_{20}=\ddot{\varphi} \pm \ddot{O}_{2}$

The second time is now derived (42) and the system (47) is obtained:

$$
\left\{\begin{array}{l}
2 \cdot d_{3} \cdot d \cdot \cos M=d_{3}^{2}-d_{2}^{2}+d^{2} \\
2 \cdot d_{3} \cdot \dot{d} \cdot \cos M-2 \cdot d_{3} \cdot d \cdot \sin M \cdot \dot{M}=2 \cdot d \cdot \dot{d} \\
\Rightarrow d_{3} \cdot d \cdot \sin M \cdot \dot{M}=d_{3} \cdot \dot{d} \cdot \cos M-d \cdot \dot{d} \\
\ddot{M}= \\
\frac{\ddot{d} d_{3} \cos M-\ddot{d} d-2 \dot{d}_{3} \sin M \cdot \dot{M}-d_{d_{3}} \cos M \cdot \dot{M}^{2}-\dot{d}^{2}}{d_{3} \cdot d \cdot \sin M}
\end{array}\right.
$$

The relationship (43) is again obtained with time and the expression (48) of the absolute angular acceleration $\varepsilon_{3} \equiv \varepsilon_{30}$ which is determined with $\ddot{\varphi}$ and $\ddot{M}$.

$\ddot{\varphi}$ it is determined from the system (44) and $\ddot{M}$ withdrawn from the system (47) and needs and the $\ddot{d}$ which is extracted from the system (44):

$$
\begin{aligned}
& \omega_{30} \equiv \ddot{\varphi}_{30}=\ddot{\varphi} \mp \dot{M} \\
& \varepsilon_{3} \equiv \varepsilon_{30}=\dot{\omega}_{30} \equiv \ddot{\varphi}_{30}=\ddot{\varphi} \mp \ddot{M}
\end{aligned}
$$

\section{Discussion}

Robots have penetrated today in almost all industrial fields, being much more precise than humans in the execution of operations, but also faster, more dynamic, more stable and more resilient, working $24 \mathrm{~h}$ of the $24 \mathrm{~h}$ possible, in any season, breaks, holidays, vacations and especially without getting sick. The most important fact 
is that they can also perform special operations that man can't do. So, for example, they can work in toxic, contaminated, mined, dangerous, or airless environments (in the cosmos, under water or underground), they can also position the parts very precisely so they can be used for fine, special processing at high precision operations, excellent mechanical processing, exceptional medical operations and even in all medical operations today, helping the doctor manage the patient's surgery with amazing precision, especially when it comes to open heart, brain, kidneys, liver, etc. Robots should not be fed and yet they can have an extremely long life. They can help us conquer both the underwater spaces and the cosmic spaces. Robots have stunning work precision and a faster execution speed than a man. In addition, their very precise positioning makes robot operations a great advantage, which can no longer be neglected. In repetitive and tiring work they are irreplaceable. The most commonly used anthropomorphic robotic mechatronic systems, which are currently being used, have been studied by eliminating the heavy, matrix 3D spatial system, the study being simplified in a plan by considering the main work plan of the system and the plan, the rotation required to restore the spatial parameters of the anthropomorphic 3D system. In other words, we can greatly ease the work of the anthropomorphic robot engineer by moving from $3 \mathrm{D}$ systems to a $2 \mathrm{D}$ system. In this study we will study the inverse kinematics of the plan system, 2D, as the most important one. In general, end effector positions are known (required) and the positions of the 2D module elements and the necessary rotations of the actuators for their creation must be determined. In the kinematics we know the kinematic parameters $\mathrm{x}_{\mathrm{M}}$ and $\mathrm{y}_{\mathrm{M}}$, which represent the scaled coordinates of the point $\mathrm{M}$ (endefactor $\mathrm{M}$ ) and must be determined by analytical calculations the parameters $\varphi_{20}$ and $\varphi_{30}$.

\section{Conclusion}

The most commonly used anthropomorphic robotic mechatronic systems, which are currently being used, have been studied by eliminating the heavy, matrix 3D spatial system, the study being simplified in a plan by considering the main work plan of the system and the plan, the rotation required to restore the spatial parameters of the anthropomorphic 3D system. In other words, we can greatly ease the work of the anthropomorphic robot engineer by moving from 3D systems to a $2 \mathrm{D}$ system. In this study we will study the inverse kinematics of the plan system, 2D, as the most important one. In general, end effector positions are known (required) and the positions of the 2D module elements and the necessary rotations of the actuators for their creation must be determined. In the kinematics we know the kinematic parameters $\mathrm{x}_{\mathrm{M}}$ and $\mathrm{y}_{\mathrm{M}}$, which represent the scaled coordinates of the point $M$ (endefactor $\mathrm{M}$ ) and must be determined by analytical calculations the parameters $\varphi_{20}$ and $\varphi_{30}$.

\section{Acknowledgement}

This text was acknowledged and appreciated by Dr. Veturia CHIROIU Honorific member of Technical Sciences Academy of Romania (ASTR) PhD supervisor in Mechanical Engineering.

\section{Funding Information}

Research contract: 1-Research contract: Contract number 36-5-4D/1986 from 24IV1985, beneficiary CNST RO (Romanian National Center for Science and Technology) Improving dynamic mechanisms.

2-Contract research integration. 19-91-3 from 29.03.1991; Beneficiary: MIS; TOPIC: Research on designing mechanisms with bars, cams and gears, with application in industrial robots.

3-Contract research. GR 69/10.05.2007: NURC in 2762; theme 8: Dynamic analysis of mechanisms and manipulators with bars and gears.

4-Labor contract, no. 35/22.01.2013, the UPB, "Stand for reading performance parameters of kinematics and dynamic mechanisms, using inductive and incremental encoders, to a Mitsubishi Mechatronic System" "PN-IIIN-CI-2012-1-0389".

All these matters are copyrighted! Copyrights: 394qodGnhhtej, from 17-02-2010 13:42:18; 463-vpstuCGsiy, from 20-03-2010 12:45:30; 631-sqfsgquutm, from 2405-2010 16:15:22; 933-CrDztEfqow, from 07-01-2011 $13: 37: 52$.

\section{Author's Contributions}

This section should state the contributions made by each author in the preparation, development and publication of this manuscript.

\section{Ethics}

Authors should address any ethical issues that may arise after the publication of this manuscript.

\section{References}

Aldana, N.D., C.L. Trujillo and J.G. Guarnizo, 2013. Active and reactive power flow regulation for a grid connected vsc based on fuzzy controllers. Rev. Facultad Ingeniería, 66: 118-130.

Antonescu, P., 2003. Mecanisms. Printech, București. Antonescu, P., 1993. Synthesis of manipulators. Lito UPB, Bucureşti. 
Antonescu, P. and M. Mitrache, 1989. Contributions to the synthesis of the mechanisms used as windscreen wipers. Bucharest, 4: 23-32.

Autorenkollektiv, 1968. Getriebetechnik-VEB. Verlag Technik, Berlin.

Aversa, R., R.V.V. Petrescu, A. Apicella and F.I.T. Petrescu, 2017a. Nano-diamond hybrid materials for structural biomedical application. Am. J. Biochem. Biotechnol., 13: 34-41.

DOI: 10.3844/ajbbsp.2017.34.41

Aversa, R., R.V. Petrescu, B. Akash, R.B. Bucinell and J.M. Corchado et al., 2017b. Kinematics and forces to a new model forging manipulator. Am. J. Applied Sci., 14: 60-80. DOI: 10.3844/ajassp.2017.60.80

Aversa, R., R.V. Petrescu, A. Apicella, I.T.F. Petrescu and J.K. Calautit et al., 2017c. Something about the $\mathrm{V}$ engines design. Am. J. Applied Sci., 14: 34-52. DOI: 10.3844/ajassp.2017.34.52

Aversa, R., D. Parcesepe, R.V.V. Petrescu, F. Berto and G. Chen et al., 2017d. Process ability of bulk metallic glasses. Am. J. Applied Sci., 14: 294-301. DOI: 10.3844/ajassp.2017.294.301

Aversa, R., R.V.V. Petrescu, B. Akash, R.B. Bucinell and J.M. Corchado et al., 2017e. Something about the balancing of thermal motors. Am. J. Eng. Applied Sci., 10: 200.217. DOI: 10.3844/ajeassp.2017.200.217

Aversa, R., F.I.T. Petrescu, R.V. Petrescu and A. Apicella, 2016a. Biomimetic FEA bone modeling for customized hybrid biological prostheses development. Am. J. Applied Sci., 13: 1060-1067. DOI: 10.3844/ajassp.2016.1060.1067

Aversa, R., D. Parcesepe, R.V. Petrescu, G. Chen and F.I.T. Petrescu et al., 2016b. Glassy amorphous metal injection molded induced morphological defects. Am. J. Applied Sci., 13: 1476-1482.

DOI: 10.3844/ajassp.2016.1476.1482

Aversa, R., R.V. Petrescu, F.I.T. Petrescu and A. Apicella, 2016c. Smart-factory: Optimization and process control of composite centrifuged pipes. Am. J. Applied Sci., 13: 1330-1341.

DOI: 10.3844/ajassp.2016.1330.1341

Aversa, R., F. Tamburrino, R.V. Petrescu, F.I.T. Petrescu and M. Artur et al., 2016d. Biomechanically inspired shape memory effect machines driven by muscle like acting NiTi alloys. Am. J. Applied Sci., 13: 1264-1271.

DOI: 10.3844/ajassp.2016.1264.1271

Aversa, R., E.M. Buzea, R.V. Petrescu, A. Apicella and M. Neacsa et al., 2016e. Present a mechatronic system having able to determine the concentration of carotenoids. Am. J. Eng. Applied Sci., 9: 1106-1111.

DOI: 10.3844/ajeassp.2016.1106.1111
Aversa, R., R.V. Petrescu, R. Sorrentino, F.I.T. Petrescu and A. Apicella, 2016f. Hybrid ceramo-polymeric nanocomposite for biomimetic scaffolds design and preparation. Am. J. Eng. Applied Sci., 9: 1096-1105. DOI: 10.3844/ajeassp.2016.1096.1105

Aversa, R., V. Perrotta, R.V. Petrescu, C. Misiano and F.I.T. Petrescu et al., 2016g. From structural colors to super-hydrophobicity and achromatic transparent protective coatings: Ion plating plasma assisted $\mathrm{TiO}_{2}$ and $\mathrm{SiO}_{2}$ Nano-film deposition. Am. J. Eng. Applied Sci., 9: 1037-1045.

DOI: 10.3844/ajeassp.2016.1037.1045

Aversa, R., R.V. Petrescu, F.I.T. Petrescu and A. Apicella, 2016h. Biomimetic and evolutionary design driven innovation in sustainable products development. Am. J. Eng. Applied Sci., 9: 1027-1036. DOI: 10.3844/ajeassp.2016.1027.1036

Aversa, R., R.V. Petrescu, A. Apicella and F.I.T. Petrescu, 2016i. Mitochondria are naturally micro robots-a review. Am. J. Eng. Applied Sci., 9: 991-1002. DOI: 10.3844/ajeassp.2016.991.1002

Aversa, R., R.V. Petrescu, A. Apicella and F.I.T. Petrescu, 2016j. We are addicted to vitamins $\mathrm{C}$ and E-A review. Am. J. Eng. Applied Sci., 9: 1003-1018. DOI: 10.3844/ajeassp.2016.1003.1018

Aversa, R., R.V. Petrescu, A. Apicella and F.I.T. Petrescu, 2016k. Physiologic human fluids and swelling behavior of hydrophilic biocompatible hybrid ceramo-polymeric materials. Am. J. Eng. Applied Sci., 9: 962-972.

DOI: 10.3844/ajeassp.2016.962.972

Aversa, R., R.V. Petrescu, A. Apicella and F.I.T. Petrescu, 20161. One can slow down the aging through antioxidants. Am. J. Eng. Applied Sci., 9: 1112-1126. DOI: 10.3844/ajeassp.2016.1112.1126

Aversa, R., R.V. Petrescu, A. Apicella and F.I.T. Petrescu, 2016m. About homeopathy or «Similia similibus curentur 》. Am. J. Eng. Applied Sci., 9: 1164-1172. DOI: 10.3844/ajeassp.2016.1164.1172

Aversa, R., R.V. Petrescu, A. Apicella and F.I.T. Petrescu, 2016n. The basic elements of life's. Am. J. Eng. Applied Sci., 9: 1189-1197. DOI: 10.3844/ajeassp.2016.1189.1197

Aversa, R., F.I.T. Petrescu, R.V. Petrescu and A. Apicella, 2016o. Flexible stem trabecular prostheses. Am. J. Eng. Applied Sci., 9: 1213-1221. DOI: 10.3844/ajeassp.2016.1213.1221

Braune, R., 2000. Bewegungsdesign: Eine kernkompetenz des getriebe technikers. VDIBerichte Nr. 1567, VDI - Verlag, Dusseldorf.

Bruja, A. and M. Dima, 2001. Synthesis of kinematics of harmonics reducers with rigid front element. Proceedings of the 6th Simpson Nat. of Construction Machinery, (NCM’ 01), pp: 53-59. 
Buda, L. and C. Mateucă, 1989. Functional, cinematic and cinetostatic analysis of the lifting mechanism of the passenger carriages. Bucharest.

Cao, W., H. Ding, Z. Bin and C. Ziming, 2013. New structural representation and digital-analysis platform for symmetrical parallel mechanisms. Int. J. Adv. Robotic Sys. DOI: 10.5772/56380

Dong, H., N. Giakoumidis, N. Figueroa and N. Mavridis, 2013. Approaching behaviour monitor and vibration indication in developing a General Moving Object Alarm System (GMOAS). Int. J. Adv. Robotic Sys. DOI: $10.5772 / 56586$

Dudita, F.L., 1989. Articulated, inventive, cinematic mechanisms. Technical Publishing House, Bucharest.

Garcia, E., M.A. Jimenez, P.G. De Santos and M. Armada, 2007. The evolution of robotics research. IEEE Robot. Automat. Magaz., 14: 90-103. DOI: $10.1109 /$ MRA.2007.339608

Garcia-Murillo, M., J. Gallardo-Alvarado and E. Castillo-Castaneda, 2013. Finding the generalized forces of a series-parallel manipulator. IJARS. DOI: $10.5772 / 53824$

He, B., Z. Wang, Q. Li, H. Xie and R. Shen, 2013. An analytic method for the kinematics and dynamics of a multiple-backbone continuum robot. IJARS. DOI: $10.5772 / 54051$

Kojevnikov, S.N., 1969. Teoria mehanizmov i maşin. Izd. Maşinostroenie, Moskva.

Lederer, P., 1993. Dynamische synthese der ubertragungs-funktion eines Kurvengetriebes. Mech. Mach. Theory, 28: 23-29.

Lee, B.J., 2013. Geometrical derivation of differential kinematics to calibrate model parameters of flexible manipulator. Int. J. Adv. Robotic Sys. DOI: $10.5772 / 55592$

Lichtenheldt, W., 1995. Konstruktionslehre der Getriebe. Akademie - Verlag Berlin, 1970.

Lin, S., 1999. Getriebesynthese nach unscharfen Lagenvorgaben durch Positionierung eines vorbestimmten Getriebes. Fortschritt, Berichte VDI, Reihe 1. Nr. 313, VDI - Verlage, Dusseldorf.

Lin, W., B. Li, X. Yang and D. Zhang, 2013. Modelling and control of inverse dynamics for a 5-DOF parallel kinematic polishing machine. Int. J. Adv. Robotic Sys. DOI: 10.5772/54966

Liu, H., W. Zhou, X. Lai and S. Zhu, 2013. An efficient inverse kinematic algorithm for a PUMA560structured robot manipulator. IJARS.

DOI: $10.5772 / 56403$

Luck, K. and K.H. Modler, 1995. Getriebetechnik: Analyse, Synthese, Optimierung. 2nd Edn., Springer, New York, ISBN-10: 3540570012, pp: 367.

Manolescu, N.I., 1968. Problems of machine theory and machines. E.D.P., Bucharest.
Margine, A.L., 1999. Contributions to the geometrickinematical and dynamic synthesis of planetary gears with cylindrical gears. PhD Thesis, U.P.B.

Maros, D., 1958. Gear wheel kinematic. Technical Publishing House, Bucharest.

Flavio de Melo, L., S.F. Reis Alves and J.M. Rosário, 2012. Mobile robot navigation modelling, control and applications. Int. Rev. Modell. Simulat., 5: 1059-1068.

Mirsayar, M.M., V.A. Joneidi, R.V.V. Petrescu, F.I.T. Petrescu and F. Berto, 2017. Extended MTSN criterion for fracture analysis of soda lime glass. Eng. Fracture Mechan., 178: 50-59. DOI: 10.1016/j.engfracmech.2017.04.018

Modler, K.H. and C. Wadewitz, 2001. Synthese von raderkoppelgetriebe als vorschaltgetriebe mit definierter ungleichformigkeit. Wissenschaftliche Zeitschrift, 3: 101-106.

Modler, K.H. and C. Wadewitz, 1998. Trepte, U., Rechnergestutzte Synthese von Raderkoppelgetrieben als Vorschaltgetriebe zur Erzeugung nichtlinearer Antriebsbewegungen. Bericht zum DFG - Vorhaben Mo 537/5 - 1. TU Dresden.

Modler, K.H., 1979. Reakisierung von pilgerschritten durch zweiraderkoppel-getriebe. Dynamik und Getribetechnik.

Neumann, R., 1979. Einstellbare Raderkoppelgetriebe. Dynamik und Getribe-technik.

Neumann, R., 2001. Dreiraderkoppel: Schrittgetriebe mit zahnradern oder zahnriemen. Bucureşti.

Niemeyer, J., 2000. Das IGM - Getriebelexikon Wissensverarbeitung in der Getriebetechnik mit Hilfe der Internet - Technologie. In: IMG Kolloquium Getriebetechnik 2000, Dittrich, G. (Hrsg.), Forschung and Lehre 1972-2000, Mainz, Aachen, pp: 53-66.

Padula, F. and V. Perdereau, 2013. An on-line path planner for industrial manipulators. Int. J. Adv. Robotic Sys. DOI: 10.5772/55063

Perumaal, S. and N. Jawahar, 2013. Automated trajectory planner of industrial robot for pick-andplace task. IJARS. DOI: 10.5772/53940

Petrescu, F.I.T., 2016. Valorisation of RomanianRomanian Engineering Tradition. 1st Edn., Create Space Publisher, USA, ISBN-13: 9781537177984.

Petrescu, F.I.T., 2014. Sisteme Mecatronice Seriale, Paralele si Mixte. 1st Edn., Create Space Publisher, ISBN-13: 978-1495923814, pp: 224.

Petrescu, F.I. and R.V. Petrescu, 2011a. Memories about Flight. 1st Edn., CreateSpace, pp: 652.

Petrescu, F.I. and R.V. Petrescu, 2011b. Mechanical Systems, Serial and Parallel - Course (in romanian). 1st Edn., LULU Publisher, London, UK, ISBN 978-1-4466-0039-9, pp: 124. 
Petrescu, F.I.T. and R.V. Petrescu, 2011c. Planetary Trains (Romanian Edition). 1st Edn., CreateSpace, USA, ISBN-13: 978-1468030419, pp: 204.

Petrescu, F.I. and R.V. Petrescu, 2011d. Dynamics of Distribution Mechanisms. 1st Edn., Create Space Publisher, USA, ISBN-13: 978-1-4680-5265-7, pp: 188.

Petrescu, R.V. and F.I.T. Petrescu, 2012a. Northrop. 1st Edn., Books on Demand, ISBN-13: 978-3848209323, pp: 142.

Petrescu, F.I. and R.V. Petrescu, 2012b. New Aircraft II. 1st Edn., Books on Demand, pp: 138.

Petrescu, F.I. and R.V. Petrescu, 2012c. MecatronicaSisteme Seriale si Paralele. 1st Edn., Create Space Publisher, USA, ISBN-13: 978-1-4750-6613-5, pp: 128.

Petrescu, F.I. and R.V. Petrescu, 2012d. Kinematics of the planar quadrilateral mechanism. Engevista, 14: 345-348. DOI: 10.22409/engevista.v14i3.377

Petrescu, R.V. and F.I. Petrescu, 2013a. Lockheed Martin. 1st Edn., CreateSpace, pp: 114.

Petrescu, R.V. and F.I. Petrescu, 2013b. Northrop. 1st Edn., CreateSpace, pp: 96.

Petrescu, R.V. and F.I. Petrescu, 2013c. The Aviation History or New Aircraft I Color. 1st Edn., CreateSpace, pp: 292.

Petrescu, F.I. and R.V. Petrescu, 2013d. Cinematics of the 3R dyad. Engevista, 15: 118-124.

Petrescu, F.I. and R.V. Petrescu, 2016a. Parallel moving mechanical systems kinematics. ENGEVISTA, 18: 455-491.

Petrescu, F.I. and R.V. Petrescu, 2016b. Direct and inverse kinematics to the anthropomorphic robots. ENGEVISTA, 18: 109-124.

Petrescu, F.I. and R.V. Petrescu, 2016c. Dynamic cinematic to a structure 2R. Revista Geintec-Gestao Inovacao E Tecnologias, 6: 3143-3154.

Petrescu, F.I.T. and J.K. Calautit, 2016a. About Nano fusion and dynamic fusion. Am. J. Applied Sci., 13: 261-266. DOI: 10.3844/ajassp.2016.261.266

Petrescu, F.I. and J.K. Calautit, 2016b. About the light dimensions. Am. J. Applied Sci., 13: 321-325. DOI: 10.3844/ajassp.2016.321.325

Petrescu, F.I.T., 2009. New aircraft. Proceedings of the 3rd International Conference on Computational Mechanics, Oct. 29-30, Brasov, Romania.

Petrescu, F.I.T., 2012a. Cold Nuclear Fusion. 1st Edn., Create Space, USA, ISBN-13: 1478234261/9781478234265, pp: 80.

Petrescu, F.I.T., 2012b. Particle annihilation-a source of renewable energy?

Petrescu, F.I.T., 2012c. Particle annihilation-a source of renewable energy? Infinite Energy journal.
Petrescu, F.I., 2012d. Basis of Analysis and Optimization of Rigid Memory Systems - Course and Applications. 1st Edn., Create Space publisher, USA, ISBN-13: 978-1-4700-2436-9, pp: 164.

Petrescu, F.I., 2012e. Theory of Mechanisms - Course and Applications. 2nd Edn., Create Space Publisher, USA, ISBN-13: 978-1-4792-9362-9, pp: 284.

Petrescu, R.V.V., R. Aversa, A. Apicella, F. Berto and S. Li et al., 2016a. Ecosphere protection through green energy. Am. J. Applied Sci., 13: 1027-1032. DOI: 10.3844/ajassp.2016.1027.1032

Petrescu, F.I.T., A. Apicella, R.V.V. Petrescu, S.P. Kozaitis and R.B. Bucinell et al., $2016 \mathrm{~b}$. Environmental protection through nuclear energy. Am. J. Applied Sci., 13: 941-946.

DOI: 10.3844/ajassp.2016.941.946

Petrescu, R.V., R. Aversa, B. Akash, R. Bucinell and J. Corchado et al., 2017a. Modern propulsions for aerospace-a review. J. Aircraft Spacecraft Technol., 1: 1-8. DOI: 10.3844/jastsp.2017.1.8

Petrescu, R.V., R. Aversa, B. Akash, R. Bucinell and J. Corchado et al., 2017b. Modern propulsions for aerospace-part II. J. Aircraft Spacecraft Technol., 1: 9-17. DOI: 10.3844/jastsp.2017.9.17

Petrescu, R.V., R. Aversa, B. Akash, R. Bucinell and J. Corchado et al., 2017c. History of aviation-a short review. J. Aircraft Spacecraft Technol., 1: 30-49. DOI: 10.3844 /jastsp.2017.30.49

Petrescu, R.V., R. Aversa, B. Akash, R. Bucinell and J. Corchado et al., 2017d. Lockheed martin-a short review. J. Aircraft Spacecraft Technol., 1: 50-68. DOI: 10.3844 /jastsp.2017.50.68

Petrescu, R.V., R. Aversa, B. Akash, J. Corchado and F. Berto et al., 2017e. Our universe. J. Aircraft Spacecraft Technol., 1: 69-79.

DOI: 10.3844 jastsp.2017.69.79

Petrescu, R.V., R. Aversa, B. Akash, J. Corchado and F. Berto et al., 2017f. What is a UFO? J. Aircraft Spacecraft Technol., 1: 80-90. DOI: $10.3844 /$ jastsp. 2017.80 .90

Petrescu, R.V., R. Aversa, B. Akash, J. Corchado and F. Berto et al., 2017g. About bell helicopter FCX-001 concept aircraft-a short review. J. Aircraft Spacecraft Technol., 1: 91-96. DOI: 10.3844 /jastsp.2017.91.96

Petrescu, R.V., R. Aversa, B. Akash, J. Corchado and F. Berto et al., 2017h. Home at airbus. J. Aircraft Spacecraft Technol., 1: 97-118. DOI: $10.3844 /$ jastsp.2017.97.118

Petrescu, R.V., R. Aversa, B. Akash, J. Corchado and F. Berto et al., 2017i. Airlander. J. Aircraft Spacecraft Technol., 1: 119-148.

DOI: $10.3844 /$ jastsp.2017.119.148 
Petrescu, R.V., R. Aversa, B. Akash, J. Corchado and F. Berto et al., 2017j. When boeing is dreaming-a review. J. Aircraft Spacecraft Technol., 1: 149-161. DOI: 10.3844 /jastsp.2017.149.161

Petrescu, R.V., R. Aversa, B. Akash, J. Corchado and F. Berto et al., 2017k. About Northrop Grumman. J. Aircraft Spacecraft Technol., 1: 162-185. DOI: 10.3844/jastsp.2017.162.185

Petrescu, R.V., R. Aversa, B. Akash, J. Corchado and F. Berto et al., 20171. Some special aircraft. J. Aircraft Spacecraft Technol., 1: 186-203. DOI: $10.3844 /$ jastsp.2017.186.203

Petrescu, R.V., R. Aversa, B. Akash, J. Corchado and F. Berto et al., 2017m. About helicopters. J. Aircraft Spacecraft Technol., 1: 204-223. DOI: $10.3844 /$ jastsp.2017.204.223

Petrescu, R.V., R. Aversa, B. Akash, F. Berto and A. Apicella et al., 2017n. The modern flight. J. Aircraft Spacecraft Technol.

Petrescu, R.V., R. Aversa, B. Akash, F. Berto and A. Apicella et al., 2017o. Sustainable energy for aerospace vessels. J. Aircraft Spacecraft Technol.

Petrescu, R.V., R. Aversa, B. Akash, F. Berto and A. Apicella et al., 2017p. Unmanned helicopters. J. Aircraft Spacecraft Technol.

Petrescu, R.V., R. Aversa, B. Akash, F. Berto and A. Apicella et al., 2017q. Project HARP. J. Aircraft Spacecraft Technol.

Petrescu, F.I., B. Grecu, A. Comanescu and R.V. Petrescu, 2009. Some mechanical design elements. Proceeding of the International Conference on Computational Mechanics and Virtual Engineering, (MEC' 09), Braşov, pp: 520-525.

Popescu, I., 1977. Design of planar mechanisms. Scrisul Românesc Publishing House of Craiova.

Reddy, P., K.V. Shihabudheen and J. Jacob, 2012. Precise non linear modeling of flexible link flexible joint manipulator. IReMoS, 5: 1368-1374.

Rehwald, W. and K. Luck, 2000. Kosim Koppelgetriebesimulation. Fortschritt Berichte VDI, Reihe 1, Nr. 332. VDI Verlag, Dusseldorf.
Rehwald, W. and K. Luck, 2001. Betrachtungen zur zahl der koppelgetribetypen. Wissenschaftliche Zeitschrift der, 50: 107-115.

Stoica, I.A., 1977. Gear Wheel Interference. 1st Edn., DACIA Publishing House, Cluj-Napoca.

Şaskin, A.G., 1971. Zubciato rîciajnîe mehanizmî. Izd. Maşinostroenie, Moskva.

Şaskin, A.G., 1963. Sintezu zubciato-rîciajnîh mehanizmov s vâstoem. Teoria Maşin I Mehanizmov, 94-95: 88-110.

Tabaković, S., M. Zeljković, R. Gatalo and A. Zeljković Živković, 2013. Program suite for conceptual designing of parallel mechanism-based robots and machine tools. Int. J. Adv. Robotic Sys. DOI: $10.5772 / 56633$

Tang, X., D. Sun and Z. Shao, 2013. The structure and dimensional design of a reconfigurable PKM. IJARS. DOI: 10.5772/54696

Tong, G., J. Gu and W. Xie, 2013. Virtual entity-based rapid prototype for design and simulation of humanoid robots. Int. J. Adv. Robotic Sys. DOI: $10.5772 / 55936$

Tutunaru, D., 1969. Rectangular and Inverse Planar Mechanisms. 1st Edn., Technical Publishing House, Bucharest.

Wang, K., M. Luo, T. Mei, J. Zhao and Y. Cao, 2013. Dynamics analysis of a three-DOF planar serialparallel mechanism for active dynamic balancing with respect to a given trajectory. Int. J. Adv. Robotic Sys. DOI: 10.5772/54201

\section{Source of Figures}

Petrescu, 2014. 